\title{
Evaluación del efecto de las levaduras vitivinícolas biofungicidas sobre la germinación de semillas y crecimiento de plántulas de lechugas (Lactuca sativa $\mathrm{L}$.) in vitro. Análisis de fitotoxicidad Evaluation of the effect of viticulture biofungicide yeasts on the seed germination and growth of lettuce seedlings (Lactuca sativa L.) in vitro. Phytotoxicity analysis
}

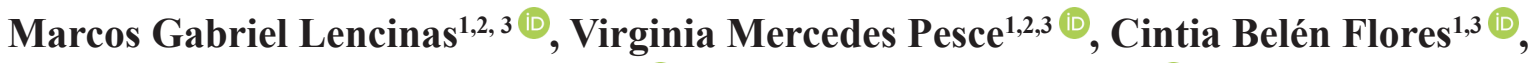 \\ Fabio Vazquez ${ }^{1,2}$ (1) María Cristina Nally ${ }^{1,2,3} \div$ (iD
}

\footnotetext{
${ }^{1}$ Instituto de Biotecnología, Facultad de Ingeniería, Universidad Nacional de San Juan. Av. Libertador San Martín 1109 oeste. San Juan, Argentina. *Autora para correspondencia (cristinanally@yahoo.com.ar)

${ }^{2}$ Departamento de Ingeniería Agronómica, Facultad de Ingeniería, Universidad Nacional de San Juan. Calle 11 y Vidart. Pocito, San Juan, Argentina.

${ }^{3}$ Consejo Nacional de Investigaciones Científicas y Técnicas (CONICET). Godoy Cruz 2290. Buenos Aires, Argentina.
}

\section{RESUMEN}

Botrytis cinerea puede afectar a la lechuga tanto en condiciones de invernadero como en condiciones de campo. Levaduras vitivinícolas presentaron actividad antifúngica frente a $B$. cinerea de lechuga in vitro. Sin embargo, se desconoce si estas levaduras afectan la germinación de semillas o crecimiento de las plántulas de lechuga. Objetivo: Evaluar el efecto de las levaduras vitivinícolas sobre la germinación de semillas y crecimiento de plántulas emergentes de lechuga (L. sativa), in vitro. Las levaduras se inocularon puntalmente sobre semillas de lechugas en bandejas plásticas. A los 4 y 7 días, se evaluó $\%$ de semillas germinadas, longitud de radícula, hipocótilo y cotiledones. También se evaluó el índice de vigor (IV) (7 días). Resultados: A los 4 días, cuatro levaduras BSchp67, BSc92, BSc121, BSc203 promovieron significativamente la germinación de semillas de lechuga en comparación con el control. De estas levaduras, dos incrementaron la longitud de los cotiledones. A los 7 días, seis levaduras BSc16, BSc61, BSchp67, BSc92, BSc121, BSc203 incrementaron el $\%$ de semillas germinadas y la longitud del hipocótilo. A los 4 y 7 días ninguna de las levaduras ensayadas incrementó significativamente la longitud de la radícula. Las plantas pre-inoculadas con las levaduras vitivinícolas presentaron un IV similar al control, excepto las plántulas inoculadas con BSc81, donde fue menor. Conclusiones: El efecto de las levaduras sobre la germinación y crecimiento de la lechuga fue variable. Al finalizar el ensayo BSc5, BSc47, BSc68, BSc49, BSc56 y BSc92 no afectaron negativamente la tasa de germinación, el crecimiento vegetativo (radícula, hipocótilo, cotiledones), ni el vigor de las plántulas de lechuga, por lo tanto, podrían utilizarse como biofungicidas. Las últimas tres cepas mencionadas anteriormente promovieron el crecimiento del hipocótilo (día 7). Estos datos sugieren la posibilidad de empleo de estas levaduras como biofungicidas y como posibles promotores del crecimiento vegetal (doble función).

Palabras clave: agentes de biocontrol, vegetal, toxicidad, inhibidores de crecimiento, promotores de crecimiento.

\section{SUMMARY}

Botrytis cinerea can affect lettuce under both greenhouse and field conditions. Vitiviniculture yeasts Saccharomyces cerevisiae and Schizosaccharomyces pombe showed activity against $B$. cinerea isolated from lettuce, in vitro. However, it is unknown whether these yeasts affect seed germination and/or growth of lettuce seedlings. Objective: To evaluate the effect
Cita recomendada:

Lencinas, M. G., V. M. Pesce, C. B. Flores, F. Vazquez y M. C. Nally. 2020. Evaluación del efecto de las levaduras vitivinícolas biofungicidas sobre la germinación de semillas y crecimiento de plántulas de lechugas (Lactuca sativa L.) in vitro. Análisis de fitotoxicidad. Terra Latinoamericana Número Especial 38-3: 715-724.

DOI: https://doi.org/10.28940/terra.v38i3.648
Recibido: 07 de octubre de 2019. Aceptado: 12 de diciembre de 2019. Publicado en Terra Latinoamericana 38: 715-724. 
of vitiviniculture yeasts on seed germination and growth of seedlings emerging from lettuce (L. sativa), in vitro. The yeasts were inoculated on lettuce seeds incubated in plastic trays. At 4 and 7 days, the $\%$ of germinated seeds, length of radicle, hypocotyl and cotyledons were evaluated. The vigor index (IV) (7 days) was also evaluated. Results: After 4 days, four yeasts BSchp67, BSc92, BSc121 and BSc203 significantly promoted the germination of lettuce seeds compared to the control. Of these yeasts, two increased the cotyledon length. At 7 days, six yeasts BSc16, BSc61, BSchp67, BSc92, $\mathrm{BSc} 121$ and $\mathrm{BSc} 203$ increased the $\%$ of germinated seeds and the hypocotyl length. At 4 and 7 days none of the yeasts assayed significantly increased the radicle length. The seedlings pre-inoculated with the wine yeasts presented an IV similar to the control, except the seedlings inoculated with BSc81, where the IV was smaller. Conclusions: The effect of yeasts on the lettuce germination and growth was variable. At the end of the assay, yeasts $\mathrm{BSc} 5, \mathrm{BSc} 47, \mathrm{BSc} 68, \mathrm{BSc} 49, \mathrm{BSc} 56$ and $\mathrm{BSc} 92$ did not negatively affect the germination rate, vegetative growth (radicle, hypocotyl, cotyledons), nor the vigor of the lettuce seedlings, therefore they could be used as possible biocontrol agents. The last three strains mentioned above promoted hypocotyl growth (day 7). These data suggest the possibility of using these yeasts as biofungicides and as possible plant growth promoters (dual function).

Index word: biocontrol agents, vegetable, toxicity, growth inhibitors, growth promoters.

\section{INTRODUCCIÓN}

La lechuga (Lactuca sativa L.) es una especie anual y autógama, perteneciente a la familia Asteraceae (Koopman et al., 1998). A nivel mundial, en los últimos años, el cultivo de lechuga se ha incrementado considerablemente, debido al aumento del consumo de hortalizas de cuarta gama o mínimamente procesadas. En 1993 se produjeron $12500000 \mathrm{Mg}$ de lechuga y en el 2017 se duplicó la producción en relación al año 1993. China es el mayor productor de lechugas del mundo (FAOSTAT, 2019). En Argentina, la lechuga, el tomate y la papa se encuentran entre las hortalizas más consumidas y cultivadas del país (Szczesny et al., 2014). Algunos microorganismos pueden afectar la calidad de la lechuga entre ellos podemos citar a Sclerotinia sclerotorium, Sclerotinia minor,
Sclerotium rolfsii, Septoria lactucae, Bremia lactucae, Microdochium panattonianum, Mycocentrospora acerina, Rhizoctornia solani, Cercospora longissima, Stemphylium botryosum, Erysiphe cichoracearum, Alternaria spp., Fusarium oxysporum, Phytophthora spp., Pythium aphanidermatum, Pythium uncinulatum, Phymatotrichopsis omnivorum, Verticillium dahliae y Botrytis cinerea, entre otros (Raid, 2004; Mou, 2008). $B$. cinerea puede atacar diferentes partes de la planta de la lechuga como hojas y raíces (Card, 2005; Yahaya et al., 2015), y en algunos casos impide la emergencia de la plántula desde la semilla (Granval y Gaviola, 1991; Sowley et al., 2009). Tradicionalmente, el control de $B$. cinerea se ha basado en prácticas culturales combinadas con el uso intensivo de fungicidas químicos, tanto de amplio espectro como específicos. Sin embargo, la aplicación de fungicidas químicos presenta varios problemas como la relativa facilidad con la que emergen porciones de poblaciones resistentes a algunos fungicidas químicos (Williamson et al., 2007). Otro problema que ocasionan estos fungicidas es que producen efectos adversos sobre el ambiente y la salud humana (Elmer y Reglinski, 2006). El uso de microorganismos antagonistas ha sido estudiado por grupos de investigación de todo el mundo y representa una de las bio-estrategias con mayor potencial para el control integrado de enfermedades fúngicas (Droby et al., 2009; Nicot, 2011). Las levaduras han demostrado actividad antagónica frente a cepas de B. cinerea aisladas de diferentes patosistemas como el de la uva (Vitis vinifera L.) (Rabosto et al., 2006; Nally et al., 2012; Calvo-Garrido et al., 2013), tomate (Solanum lycopersicum L.) (Elead et al., 1994; Dik y Elead, 1999; Dal Bello et al., 2008), frutilla (Fragaria $\times$ ananassa Duch.) (Huang et al., 2011; Sylla et al., 2015) y pepino (Cucumis sativus L.) (Dik y Elead, 1999), entre otros. En el Instituto de BiotecnologíaFacultad de Ingeniería-Universidad Nacional de San Juan (IBT-FI-UNSJ) se seleccionaron 16 levaduras vitivinícolas (15 S. cerevisiae, 1 Sch. pombe) que presentaban actividad antifúngica frente a $B$. cinerea aisladas de lechuga (Nally et al., 2018), in vitro. Hasta el momento se desconoce si estas levaduras afectan o no el crecimiento vegetativo de esta hortaliza. Existen reportes sobre levaduras que afectan positivamente el crecimiento vegetativo de diferentes plantas. Algunos investigadores mencionaron que levaduras promovieron el crecimiento vegetativo de la remolacha azucarera (B. vulgaris L.) El-Tarabily (2004), 
pimiento (C. annuum L.) (El-Fawy y Ahmed, 2015), haba ( $V$. faba L.) (El-Wakil et al., 2009), además de biocontrolar hongos fitopatógenos (doble función). Algunos investigadores como Holley et al. (1984) reportaron que levaduras pertenecientes al género Nematospora afectaron negativamente la calidad de semillas de mostaza (Brassica juncea L.), inhibiendo la germinación. De acuerdo con la bibliografía consultada no existen, hasta el momento, antecedentes sobre levaduras que promuevan el crecimiento vegetativo y que sean biocontroladoras de $B$. cinerea en lechuga. A partir de dicha situación se establece el siguiente objetivo general: Objetivo: Evaluar el efecto de las levaduras vitivinícolas sobre la germinación de semillas y crecimiento de plántulas emergentes de lechuga (L. sativa), in vitro.

\section{MATERIALES Y MÉTODOS}

\section{Levaduras}

Se ensayaron 16 levaduras que presentaron actividad antifúngica frente a $B$. cinerea (Nally et al., 2018). Estas levaduras pertenecen a las especies $S$. cerevisiae (BSc15, BSc16, BSc31, BSc47, BSc49, BSc56, BSc61, BSc64, BSc68, BSc81, BSc92, BSc121, BSc140, BSc175, BSc203) y $S$. pombe (BSch67). Se aislaron de mostos de uva en fermentación de bodegas de la provincia de San Juan, Argentina y se identificaron a nivel molecular (Nally et al., 2012). Estos microorganismos pertenecen al cepario del Instituto de Biotecnología-FI-UNSJ- San Juan. Argentina.

Las levaduras se inocularon en frascos Erlenmeyer de $150 \mathrm{~mL}$ de capacidad con $25 \mathrm{~mL}$ de medio líquido YEPD (extracto de levadura $10 \mathrm{~g} \mathrm{~L}^{-1}$, peptona $20 \mathrm{~g} \mathrm{~L}^{-1} \mathrm{y}$ dextrosa $\left.20 \mathrm{~g} \mathrm{~L}^{-1}\right)$ y se colocaron en agitación $(250 \mathrm{rpm})$ durante $8-12$ h a $25^{\circ} \mathrm{C}$, hasta fase exponencial. A partir de cultivos activos de levaduras se realizaron conteos de células de levaduras en cámara de Neubauer, se centrifugaron y posteriormente se realizaron diluciones con agua destilada estéril hasta obtener una concentración final de $10^{6} \mathrm{cel} \mathrm{mL}^{-1}$.

\section{Evaluación del Efecto de las Levaduras sobre la Germinación de Semillas de Lechuga y Crecimiento de la Plántula Emergente en Bandejas de Plástico}

Se evaluó la germinación de semillas según las reglas de análisis de semillas de "International Seed Testing
Association" (ISTA, 2017). Las semillas de lechuga se esterilizaron con hipoclorito de sodio al $1 \%$ durante 10 min y luego se lavaron dos veces con agua destilada estéril. Las semillas desinfectadas se colocaron sobre papel humedecido con $6 \mathrm{~mL}$ de agua destilada estéril en cajas de plástico con tapa. Posteriormente las levaduras fueron inoculadas puntualmente $\left(10 \mu \mathrm{L}, 10^{6} \mathrm{cel} \mathrm{mL}^{-1}\right)$ sobre cada semilla. Las cajas se incubaron en cámara de crecimiento vegetal a $20{ }^{\circ} \mathrm{C}$ con alternancia de luz (12 h de luz/12 h de oscuridad) y $90 \%$ humedad relativa. Se consideró una semilla germinada cuando el largo de la radícula alcanzó más de $3 \mathrm{~mm}$. Se evaluó la capacidad germinativa de 400 semillas por tratamiento ( 8 bandejas plásticas con 50 semillas cada una) a los 4 y 7 días de haber comenzado el ensayo mediante la siguiente Ecuación 1 (ISTA, 2017):

$$
\% \text { de germinación }=\left(\frac{N \text { o de semillas germinadas }}{N \text { 을 } \text { semillas totales }}\right) \times 100
$$

Control. Semillas inoculadas solo con agua destilada estéril $(20 \mu \mathrm{L})$ e incubadas en las mismas condiciones anteriormente mencionadas.

A 4 y 7 días de haber comenzado el ensayo se tomaron mediciones con un calibre digital en las plántulas emergentes tratadas con y sin levaduras (longitud en $\mathrm{cm}$ de la radícula, hipocótilo y cotiledones). La medida de alargamiento de la radícula se consideró desde el nudo (región de transición más gruesa entre la radícula y el hipocótilo) hasta el vértice de la radícula. Se realizaron tres réplicas por tratamiento (cada réplica conformada por 400 semillas). En la Figura 1 se muestra cómo crecen las plántulas de lechugas sobre papel humedecido con agua destilada estéril en bandejas plásticas durante 7 días a $20^{\circ} \mathrm{C}$, con fotoperiodo pre establecido.

\section{Índice de Vigor (IV)}

El índice del vigor (IV) de las semillas tratadas con y sin levaduras (ITEM 2) se calculó a los 7 días mediante la siguiente Ecuación 2 (Amprayn et al., 2012):

IV = (Promedio largo de raíz + Promedio longitud del hipocótilo $)$ $\times$ \% de germinación 


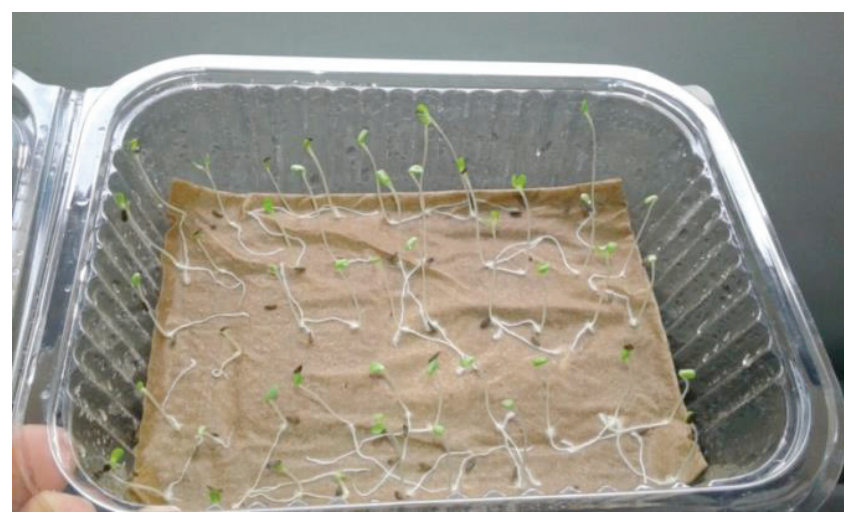

Figura 1. Plántulas de lechuga de 7 días de crecimiento previamente inoculadas en forma puntual con levaduras, incubada a $20^{\circ} \mathrm{C}$ con alternancia de luz $(12 \mathrm{~h}$ luz/12 $\mathrm{h}$ oscuridad) y $90 \%$ humedad relativa.

Figure 1. Lettuce seedlings of 7 days of growth previously inoculated punctually with yeasts, incubated at $20{ }^{\circ} \mathrm{C}$ with alternating light $(12 \mathrm{~h}$ light/12 $\mathrm{h}$ dark) and $90 \%$ relative humidity.

\section{Análisis Estadístico}

Los resultados que cumplieron con los supuestos de normalidad, homogeneidad de la varianza e independencia se sometieron a un análisis de la varianza (ANOVA) unifactorial, con diseño completamente al azar (InfoStat, 2018). La prueba de separación de medias se realizó a posteriori por el test de Tukey, con un nivel de significancia de $P<0.05$. Los resultados que no se ajustaron a los supuestos del ANOVA fueron sometidos a un análisis de la varianza no paramétrica con la prueba de Kruskal Wallis (InfoStat, 2018).

\section{RESULTADOS Y DISCUSIÓN}

\section{Evaluación del Efecto de las Levaduras Vitivinícolas sobre la Germinación de Semillas y Crecimiento de las Plántulas Emergentes de Lechuga in vitro}

A los cuatro días de haber iniciado el ensayo de germinación de las semillas de lechuga sobre papel húmedo, los simientes inoculados con las levaduras S. cerevisiae BSc92, BSc121, BSc203 y Sch. pombe BSchp67 mostraron un porcentaje de germinación significativamente mayor en relación al control $(P<0.0001)$ (Cuadro 1). Las semillas inoculadas con las levaduras BSc16, BSc49, BSc64 y BSc68 evidenciaron una tasa germinativa (entre 86.09 y 94.06\%) significativamente inferior en relación al control (96.03\%). Las demás levaduras ensayadas no aumentaron o disminuyeron la tasa de germinación (Cuadro 1). A los siete días se observó que las semillas inoculadas con las levaduras BSc5, BSc16, BSc61, BSc64, BSchp67, BSc68, BSc92, BSc121 у BSc203 mostraron valores de $100 \%$ de germinación, los cuales fueron significativamente superiores al control $(P<0.0001)$ (Cuadro 2). Las semillas inoculadas con las levaduras restantes no mostraron diferencias significativas en relación al control (Cuadro 2).

Un método simple para la detección de microorganismos fitotóxicos o promotores de crecimiento consiste en la inoculación de estos organismos sobre semillas (Kremer et al., 2006; Carvalho et al., 2007). Existen investigaciones que reportan los efectos de cultivos microbianos sobre la germinación de semillas. Reyes et al. (2008) reportaron que semillas de maíz (Zea mays L.), que habían sido previamente embebidas en una solución con Azospirillum sp. $\left(\begin{array}{lll}10^{8} & \text { cel } \mathrm{mL}^{-1}\end{array}\right)$ e incubadas durante 5 días, presentaron mayor cantidad de semillas germinadas en relación al control, utilizando como sustrato agar-agua al $8 \%$. Blanco et al. (2018) determinaron que semillas de pimiento (Capsicum annuum L.), que habían sido previamente embebidas en los aislados rizobianos RmBorbollón (Ochrobactrum sp.) y ME01 (Ochrobactrum sp.), mostraron un incremento significativo en la tasa de germinación con respecto al control, en similares condiciones a las ensayadas en este trabajo (cuatro días de ensayo sobre papel humedecido). Posteriormente, al séptimo día observaron un aumento significativo del porciento de semillas germinadas (entre un 1.74 y $2.03 \%$ ) en las semillas inoculadas con las cepas Alf (Pseudomonas sp.), ME01 (Ochrobactrum sp.), Leu2A y Med (Bradyrhizobium sp.), en relación al control. Estos resultados son comparables con los obtenidos en el presente trabajo debido que a los 4 días de haber comenzado el ensayo las semillas de lechugas, inoculadas previamente con levaduras Sch. pombe (BSchp67) y S. cerevisiae (BSc92, BSc121 y BSc203), incrementaron significativamente su tasa germinativa en relación al control (Cuadro 1). Posteriormente, a los 7 días, las levaduras anteriormente mencionadas y otras levaduras como $S$. cerevisiae $\mathrm{BSc} 5, \mathrm{BSc} 16$, BSc61, BSc64, BSc68, BSc92, aumentaron el porcentaje de semillas germinadas $(100 \%$ de semillas germinadas) con respecto al control (Cuadro 2). 
Cuadro 1. Evaluación del efecto de las levaduras vitivinícolas sobre la germinación de semillas y sobre el crecimiento de las plántulas emergentes de lechuga (longitud de radícula, hipocótilo, cotiledones), incubadas durante 4 días a $20^{\circ} \mathrm{C}$, sobre papel humedecido (bandejas plásticas).

Table 1. Evaluation of the effect of wine yeasts on seed germination and on the growth of emerging lettuce seedlings (radicle length, hypocotyl, cotyledons), incubated for 4 days at $20^{\circ} \mathrm{C}$, on damp paper (plastic trays) .

\begin{tabular}{|c|c|c|c|c|}
\hline Levaduras & Semillas germinadas & Longitud de radícula & Longitud de hipocótilo & Longitud de cotiledones \\
\hline & $\%$ & \multicolumn{3}{|c|}{$\ldots \ldots \ldots$} \\
\hline $\mathrm{BSc} 5$ & 97.03 & $0.74(* *)$ & 1.45 & 0.42 \\
\hline BSc16 & $93.01(* *)$ & $0.82(* *)$ & $1.30(* *)$ & 0.47 \\
\hline BSc31 & 97.90 & 1.08 & $1.30(* *)$ & 0.50 \\
\hline $\mathrm{BSc} 47$ & 95.06 & $1.13(* *)$ & $1.18(* *)$ & $0.55(*)$ \\
\hline $\mathrm{BSc} 49$ & $94.04(* *)$ & 1.17 & $1.29(* *)$ & $0.56(*)$ \\
\hline BSc56 & 96.03 & 1.18 & $1.28(* *)$ & $0.54(*)$ \\
\hline BSc61 & 96.34 & $1.01(* *)$ & 1.35 & $0.54(*)$ \\
\hline BSc64 & $94.06(* *)$ & $0.89(* *)$ & $1.17(* *)$ & $0.55\left(^{*}\right)$ \\
\hline BSchp67 & $98.11(*)$ & $0.84(* *)$ & $1.31(* *)$ & $0.60(*)$ \\
\hline BSc68 & $86.09(* *)$ & $0.77(* *)$ & $1.13(* *)$ & 0.52 \\
\hline BSc 81 & 96.09 & $0.67(* *)$ & $1.07(* *)$ & $0.62(*)$ \\
\hline BSc92 & $98.02\left(^{*}\right)$ & $0.54(* *)$ & $1.26(* *)$ & 0.52 \\
\hline $\mathrm{BSc} 121$ & $100(*)$ & $0.82(* *)$ & $1.03(* *)$ & $0.54(*)$ \\
\hline BSc140 & 96.05 & $0.60(* *)$ & 1.36 & 0.50 \\
\hline BSc175 & 96.11 & $0.97(* *)$ & $1.05(* *)$ & $0.58(*)$ \\
\hline BSc203 & $98.15\left(^{*}\right)$ & $0.67(* *)$ & $1.26(* *)$ & 0.47 \\
\hline Control $\left(\mathrm{H}_{2} \mathrm{O}\right)$ & 96.03 & 1.53 & 1.64 & 0.40 \\
\hline
\end{tabular}

* incremento significativo, ** disminución significativa; en relación al control.

* significant increase, ** significant decrease; in relation to control.

Bab'eva y Belyanin (1966) también reportaron que la germinación de semillas de repollo (Brassica oleracea var. capitata L.) se incrementó cuando las mismas se inocularon levaduras pertenecientes a la especie Torulopsis sp. Algunos autores relacionan el aumento de la germinación de semillas con la presencia de giberelinas, ya que esta fitohormona induce la hidrólisis del almidón y otras moléculas provocando la liberación de solutos (monómeros), los cuales son absorbidos por el escutelo y transportados al embrión, permitiendo el desarrollo del mismo (Matilla, 2008). Algunos autores mencionaron que levaduras pertenecientes a las especies Candida valida, Rhodotorula glutinis y Trichosporon asahii produjeron giberelinas (El-Tarabily, 2004). Se ha informado que $S$. cerevisiae es capaz de sintetizar dicha fitohormona bajo condiciones in vitro (Tawfiq et al., 2018).

El efecto de las levaduras sobre la longitud de la radícula emergente fue variable. A los 4 días las semillas que fueron inoculadas con las levaduras BSc31, BSc49 y BSc56 presentaron radículas con longitudes similares a la del control $(P>0.05)$ (Cuadro 1). La aplicación de las levaduras restantes provocó una disminución significativa en la longitud de las mismas entre un 26.14 y $64.7 \%(P<0.0001)$ (Cuadro 1). Luego, a los 7 días se observó que la longitud de las radículas, en las plántulas que previamente fueron inoculadas con las levaduras $\mathrm{BSc} 5, \mathrm{BSc} 47, \mathrm{BSc} 49, \mathrm{BSc} 56, \mathrm{BSc} 68$ y $\mathrm{BSc} 92$, no varió en forma significativa respecto del control $(P>0.05)$ (Cuadro 2). Las demás levaduras ensayadas disminuyeron significativamente el largo de la radícula de las plántulas emergentes entre 41.09 y $66.43 \%$ en relación al control $(P<0.0001)$ (Cuadro 2). Ninguna de las levaduras incrementó la longitud de la radícula, a los 4 y 7 días (Cuadros 1 y 2).

Con respecto a la longitud del hipocótilo, a los 4 días, las semillas previamente inoculadas con BSc5, BSc61 y BSc140 no mostraron diferencias 
Cuadro 2. Evaluación del efecto de las levaduras vitivinícolas sobre la germinación de semillas y sobre el crecimiento de las plántulas emergentes de lechuga (longitud de radícula, hipocótilo, cotiledones, índice de vigor), incubadas durante 7 días a $20^{\circ} \mathrm{C}$, sobre papel humedecido (bandejas plásticas).

Table 2. Evaluation of the effect of wine yeasts on seed germination and on the growth of emerging lettuce seedlings (radicle length, hypocotyl, cotyledons, vigor index), incubated for 7 days at $20^{\circ} \mathrm{C}$, on wetted paper (plastic trays).

\begin{tabular}{|c|c|c|c|c|c|}
\hline Levaduras & $\begin{array}{c}\text { Semillas } \\
\text { germinadas }\end{array}$ & $\begin{array}{c}\text { Longitud } \\
\text { de radícula }\end{array}$ & $\begin{array}{l}\text { Longitud de } \\
\text { hipocótilo }\end{array}$ & $\begin{array}{l}\text { Longitud de } \\
\text { cotiledones }\end{array}$ & Índice de vigor (IV) \\
\hline & $\%$ & \multicolumn{4}{|c|}{ 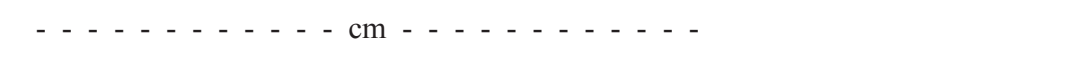 } \\
\hline BSc5 & $100(*)$ & 1.42 & 0.70 & 0.50 & 211.8 \\
\hline $\mathrm{BSc} 16$ & $100(*)$ & $0.99(* *)$ & $0.98(*)$ & 0.53 & 196.6 \\
\hline $\mathrm{BSc} 31$ & 98.3 & $0.96(* *)$ & $0.96(*)$ & 0.48 & 188.36 \\
\hline $\mathrm{BSc} 47$ & 96.2 & 1.13 & 0.73 & 0.46 & 178.56 \\
\hline $\mathrm{BSc} 49$ & 98.08 & 1.38 & $0.86(*)$ & 0.51 & 219.13 \\
\hline $\mathrm{BSc} 56$ & 98.03 & 1.17 & $1.02(*)$ & 0.50 & 213.05 \\
\hline BSc61 & $100(*)$ & $0.78(* *)$ & $0.75(*)$ & 0.48 & 153.6 \\
\hline BSc64 & $100(*)$ & $0.96(* *)$ & 0.65 & 0.42 & 161.8 \\
\hline BSchp67 & $100(*)$ & $0.90(* *)$ & $0.80(*)$ & 0.51 & 169.15 \\
\hline BSc68 & $100(*)$ & 1.29 & 0.64 & 0.51 & 193.2 \\
\hline $\mathrm{BSc} 81$ & 98.12 & $0.60(* *)$ & 0.69 & 0.42 & $127.01(* *)$ \\
\hline $\mathrm{BSc} 92$ & $100(*)$ & 1.02 & $0.76(*)$ & 0.46 & 178.4 \\
\hline $\mathrm{BSc} 121$ & $100(*)$ & $0.63(* *)$ & $0.91(*)$ & 0.52 & 154.02 \\
\hline BSc140 & 98.11 & $0.76(* *)$ & $0.86(*)$ & $0.55(*)$ & 158.37 \\
\hline BSc175 & 98.15 & $0.96(* *)$ & $0.87(*)$ & 0.46 & 179.34 \\
\hline $\mathrm{BSc} 203$ & $100(*)$ & $0.97(* *)$ & $0.85(*)$ & 0.52 & 182.2 \\
\hline Control $\left(\mathrm{H}_{2} \mathrm{O}\right)$ & 98.03 & 1.46 & 0.50 & 0.47 & 192.67 \\
\hline
\end{tabular}

* incremento significativo, ${ }^{* *}$ disminución significativa; en relación al control. Fila sombreada con gris indica que la levadura no afectó negativamente el crecimiento vegetativo de la plántula de lechuga (radícula, hipocótilo, cotiledones, vigor), en relación al control.

* significant increase, ${ }^{* *}$ significant decrease; in relation to control. Row shaded with gray indicates that the yeast did not negatively affect the vegetative growth of the lettuce seedling (radicle, hypocotyl, cotyledons, vigor), in relation to the control.

significativas en comparación al control. Las demás levaduras provocaron una reducción significativa en la longitud de los mismos entre un 20.12 y $37.19 \%$ $(P<0.0001)$ (Cuadro 1). A los 7 días se evidenció que las plántulas que fueron previamente inoculadas con las levaduras S. cerevisiae (BSc16, BSc31, BSc49, BSc56, BSc61, BSc92, BSc121, BSc140, BSc175, BSc203) y Sch. pombe BSchp67 incrementaron significativamente la longitud del hipocótilo entre un 50 y $104 \%$ en comparación con el control $(P<0.0001)$. Las levaduras restantes no afectaron en forma significativa el crecimiento del hipocótilo (Cuadro 2).

En cuanto a la longitud de los cotiledones, las mediciones a los 4 días indicaron que las levaduras ensayadas disminuyeron significativamente la longitud de los cotiledones entre un 37.19 y $20.12 \%$ con respecto al control $(P<0.001)$, excepto en las plántulas que fueron pre-inoculadas con BSc5, BSc61, BSc140. Los cotiledones de estas plántulas presentaron largo similar al del control (Cuadro 1). Posteriormente, a los 7 días, solo el lote de semillas que fue pre-inoculado con la levadura BSc140 presentó diferencias significativas en comparación con el control $(P=0.0301)$, mostrando un aumento en la longitud de los cotiledones en un 17.02\% (Cuadro 2).

\section{Índice de Vigor (IV)}

Los índices de vigor de las semillas inoculadas con las levaduras vitivinícolas fueron similares a los del control, excepto las plántulas que fueron tratadas con la levadura BSc81, la cual tuvo un IV significativamente menor en relación al control $(P<0.001)$ (Cuadro 2). 
La evaluación del efecto de las levaduras sobre la elongación de la radícula y del hipocótilo en las plántulas, además de evaluar el porcentaje de semillas germinadas, permite ponderar la acción de compuestos producidos por microorganismos (lectinas, etileno, auxinas, citoquininas, giberelinas, poliaminas, sideróforos, etc.) presentes en niveles de concentración bajos que no son suficientes para inhibir o promover la germinación, pero que sin embargo pueden estimular o inhibir completamente los procesos de elongación de la radícula o del hipocótilo, dependiendo del modo y sitio de acción del compuesto. De esta manera, la promoción o inhibición en la elongación de la radícula e hipocótilo constituyen indicadores muy sensibles para la evaluación de efectos biológicos en vegetales, aportando información complementaria a la proporcionada al estudiar el efecto en la germinación (Sobrero y Ronco, 2004). La promoción del crecimiento de la radícula y del hipocótilo en los primeros estadios del crecimiento podría conferirle una ventaja a la plántula en una etapa crítica de su desarrollo (Noel et al., 1996). Cassán et al. (2009) reportaron que semillas de soja (Glycine max L.) y maíz (Z. mays L.), pre-inoculadas puntualmente con Azospirillum brasilense y Bradyrhizobium japonicum, mostraron un incremento significativo en la tasa de germinación y en el crecimiento de la radícula e hipocótilo a los 7 y 8 días de haber comenzado el ensayo (sustrato papel humedecido). Por otra parte, Carrillo-Sosa et al. (2017) informaron que la imbibición de semillas de tomate (S. lycopersicum L.) en una dilución de $5 \mathrm{~mL} \mathrm{~L}^{-1}$ del bioproducto $\mathrm{LEBAME}^{\circledR}$, el cual está compuesto por una combinación de Bacillus subtillis, Lactobacillus bulgaricum y $S$. cerevisiae, estimuló significativamente la elongación de la radícula y del hipocótilo un 21 y $32 \%$, respectivamente, en comparación con el control utilizando como sustrato papel de filtro humedecido. Estos reportes coinciden parcialmente con los resultados obtenidos en este ensayo debido a que las levaduras S. cerevisiae (BSc16, BSc61, BSc92, BSc121, BSc203) y $S$. pombe (BSchp67) solo incrementaron significativamente la longitud del hipocótilo en las plántulas emergentes de lechuga (Cuadro 2) y no así la longitud de la radícula emergente. El aumento en la longitud del hipocótilo observado en el presente trabajo puede deberse a la producción de auxinas (Garay-Arroyo et al., 2014). Existen reportes de que algunas cepas de $S$. cerevisiae poseen la capacidad de sintetizar esta hormona, aún en ausencia de su precursor triptófano (Rao et al., 2010; Liu et al., 2016).

En cuanto a la longitud de los cotiledones, las mediciones indicaron que las plántulas pre-inoculadas con las levaduras BSc47, BSc49, BSc56, BSc61, BSc64, BSchp67, BSc81, BSc121 y BSc175 (a los 4 días) y con BSc140 (a los 7 días) presentaron cotiledones más largos que el control correspondiente (Cuadros 1 y 2). Este efecto podría deberse a la acción de citoquininas (CKs). Las citoquininas (CKs) promueven la elongación celular en los cotiledones y una aplicación exógena estimula una expansión celular adicional (Taiz y Zeiger, 2006). Se ha reportado que $S$. cerevisiae es capaz de sintetizar dicha fitohormona bajo condiciones in vitro (Tawfiq et al., 2018). Por otro lado, se ha demostrado que la aplicación exógena de citoquininas (CKs) inhibe la elongación celular de las raíces (Taiz y Zeiger, 2006). Esto explicaría en cierto modo la inhibición del crecimiento radicular y el aumento del tamaño de los hipocótilo observado a los siete días en las plántulas que fueron previamente inoculadas con las levaduras BSc5, BSc61 y BSc140 (Cuadro 2).

El vigor de la semilla determina el rendimiento potencial de un cultivo/planta después de la siembra. Existen varias técnicas para determinar su evaluación, una de ellas es la prueba basada en el crecimiento de plántulas, en las cuales se incluyen el recuento de semillas germinadas, el crecimiento de las plántulas, entre otros (Marcos-Filho, 2015). Estas mediciones también se utilizan para detectar posibles efectos fitotóxicos de sustancias químicas como fungicidas, insecticidas y desecantes en plantas, los cuales pueden afectar el crecimiento normal de la raíz y del hipocótilo (Marcos-Filho, 2015). Gholami et al. (2009) determinaron a los siete días que las semillas de maíz (Z. mays L.), que habían sido previamente embebidas en soluciones con aislamientos pertenecientes a las especies Pseudomonas putida y A. brasilense, mostraron un aumento significativo en el índice de vigor de un $94 \mathrm{y}$ $117 \%$, respectivamente, en comparación con el control, sobre papel humedecido. Resultados similares fueron reportados por Suliasih y Widawati (2017) donde la imbibición de semillas de sorgo (Sorghum bicolor L.), con tres cultivos bacterianos por separado (Bacillus sp., Azotobacter sp. y Azospirillum sp.), produjo a los 7 días aumentos significativos en los índices de vigor entre un 11 y $44.4 \%$ en relación al control. Es importante destacar que, a diferencia del uso de bacterias, existen escasas investigaciones donde se evalúe el efecto de 
levaduras sobre el vigor de semillas. Amprayn et al. (2012) reportaron que la imbibición de semillas de arroz (O. sativa L.), en una suspensión que contenía la levadura Candida tropicalis, incrementó un 50\% el índice de vigor con respecto al control (7 días de incubación, sustrato agar-agua). En el presente trabajo, las semillas pre- inoculadas con 15 de las 16 levaduras ensayadas presentaron índices de vigor similar al del control (Cuadro 2), es decir que el rendimiento potencial de las plántulas no se vería afectado negativamente.

\section{CONCLUSIONES}

El efecto de las levaduras sobre la germinación y crecimiento de la plántula fue variable, a los 4 y 7 días. $\mathrm{Al}$ finalizar el ensayo, las levaduras vitivinícolas BSc5, BSc47, BSc49, BSc56, BSc68 y BSc92 no afectaron negativamente la tasa de germinación, el crecimiento vegetativo (radícula, hipocótilo, cotiledones) ni el vigor de las plántulas de lechuga, por lo tanto, podrían utilizarse como posibles agentes de biocontrol ya que no afectarían la producción de este cultivo. Por otra parte, cabe aclarar que, de las levaduras anteriormente mencionadas, los aislamientos BSc49, BSc56 y BSc92 promovieron el crecimiento del hipocótilo en forma significativa en relación al control (día 7). Estos datos sugieren la posibilidad de empleo de estas levaduras como biofungicidas y como promotores del crecimiento vegetal.

\section{AGRADECIMIENTOS}

Esta investigación fue financiada por los siguientes proyectos: PDTS- UNSJ (2018-2019) y PICT-20172360 PBID y por CONICET (Consejo Nacional de Investigaciones Científicas y Técnicas).

\section{LITERATURA CITADA}

Amprayn, K., M. T. Rose, M. Kecskés, L. Pereg, H. T. Nguyen, and I. R. Kennedy. 2012. Plant growth promoting characteristics of soil yeast (Candida tropicalis HY) and its effectiveness for promoting rice growth. Appl. Soil Ecol. 61: 295-299. doi: https://doi.org/10.1016/j.apsoil.2011.11.009.

Bab'eva, I. and A. I. Belyanin. 1966. Yeasts of the rhizosphere. Mikrobiologiya 35: 712-720.

Blanco, E. L., Y. Castro, A. Olivo, R. Skwierinski y F. MorontaBarrios. 2018. Germinación y crecimiento de plántulas de pimentón y lechuga inoculadas con rizobios e identificación molecular de las cepas. Bioagro 30: 207-218.
Calvo-Garrido, C., P. A. G. Elmer, I. Viñas, J. Usall, E. Bartra, and N. Teixidó. 2013. Biological control of botrytis bunch rot in organic wine grapes with the yeast antagonist Candida sake CPA1. Appl. Microbiol. 57: 356-361. doi: https://doi. org/10.1111/lam.12121.

Card, S. 2005. Biological control of Botrytis cinerea in lettuce \& strawberry crops: A thesis submitted in partial fulfilment of the requirements for the degree of Doctor of Philosophy at Lincoln University. Canterbury, New Zealand. doi: https:// doi.org/10.13140/RG.2.1.3924.2403.

Carrillo-Sosa, Y., E. Terry-Alfonso, J. Ruiz-Padrón, M. E. DíazDe Villegas y G. Delgado. 2017. Efecto del LEBAME en la germinación de semillas de tomate (Solanum lycopersicum L.). Cult. Trop. 38: 30-35.

Carvalho, D. D. C., D. F. Oliveira, R. S. B. Corréa, V. P. Campos, R. M. Guimarães, and J. L. Coimbra. 2007. Rhizobacteria able to produce phytotoxic metabolites. Braz. J. Microbiol. 38: 759765. doi: https://doi.org/10.1590/S1517-83822007000400032.

Cassán, F., D. Perrig, V. Sgroy, O. Masciarelli, C. Penna, and M. Luna. 2009. Azospirillum brasilense Az39 and Bradyrhizobium japonicum E109 inoculated singly or in combination, promote seed germination and early seedling growth in corn (Zea mays L.) and soybean (Glycine max L.). Eur. J. Soil Biol. 45: 28-35. doi: https://doi.org/10.1016/j. ejsobi.2008.08.005.

Dal Bello, G., C. Mónaco, M. C. Rollan, G. Lampugnani, N. Arteta, C. Abramoff, L. Ronco, and M. Stocco. 2008. Biocontrol of Postharvest Grey Mould on Tomato by Yeasts. J. Phytopathol. 156: 257-263. doi: https://doi.org/10.1111/ j.1439-0434.2007.01351.x.

Dik, A. J. and Y. Elad. 1999. Comparison of antagonists of Botrytis cinerea in greenhouse-grown cucumber and tomato under different climatic conditions. Eur. J. Plant Pathol. 105: 123137. doi: https://doi.org/10.1023/A:1008778213278.

Droby, S., M. Wisniewski, D. Macarisin, and C. Wilson. 2009. Twenty years of postharvest biocontrol research: Is it time for a new paradigm? Postharvest Biol. Technol. 52: 137-145. doi: https://doi.org/10.1016/j.postharvbio.2008.11.009.

Elead, Y., J. Köhl, and N. J. Fokkema. 1994. Control of infection and sporulation of Botrytis cinerea on bean and tomato by saprophytic bacteria and fungi. Eur. J. Plant Pathol. 100: 315336. doi: https://doi.org/10.1007/BF01876443.

El-Fawy, M. M. and M. S. Ahmed. 2015. Effect of soil amendment with activated yeasts on controlling Fusarium and Verticillium wilt and growth characters of pepper. J. Phytopathol. Pest Manage. 2: 60-72. doi: https://doi. org/10.13140/RG.2.2.30300.49287.

Elmer, P. A. G. and T. Reglinski. 2006. Biosuppression of Botrytis cinerea in grapes. Plant Pathol. 55: 155-177. doi: https://doi. org/10.1111/j.1365-3059.2006.01348.x.

El-Tarabily, K. A. 2004. Suppression of Rhizoctonia solani diseases of sugar beet by antagonistic and plant growthpromoting yeasts. J. Appl. Microbiol. 96: 69-75. doi: https:// doi.org/10.1046/j.1365-2672.2003.02043.x.

El-Wakil, M. A., O. A. Awadallah, M. El-Dosuky, M. A. ElMetwally, and M. S. Mohammed. 2009. The use of bread yeast as a biocontrol agent for controlling seed-borne fungi of Faba bean. Plant Pathol. J. 8: 133-143. doi: https://doi. org/10.3923/ppj.2009.133.143. 
FAOSTAT (Food and Agriculture Organization Corporate Statistical Database). 2019. Statistics Division, Crops. Food and Agriculture Organization of the United Nations. http:// www.fao.org/faostat/es/ (Consulta: febrero 20, 2019).

Garay-Arroyo, A., M. de la Paz Sánchez, B. García-Ponce, E. Álvarez-Buylla y C. Gutiérrez. 2014. La homeostasis de las auxinas y su importancia en el desarrollo de Arabidopsis thaliana. Rev. Educ. Bioquím. 33: 13-22.

Gholami, A., S. Shahsavani, and S. Nezarat. 2009. The effect of plant growth promoting rhizobacteria (PGPR) on germination, seedling growth and yield of maize. Int. J. Biol. Life Sci. 49: 19-24. doi: 10.5281/zenodo.1083385.

Granval, N. y J. C. Gaviola. 1991. Manual de producción de semillas hortícolas. Asociación Cooperadora de la Estación Experimental Agropecuaria La Consulta. INTA. Argentina.

Holley, R. A., P. Allan-Wojtas, and B. E. Phipps-Todd. 1984. Nematospora sinecauda Sp. Nov., a yeast pathogen of mustard seeds. Antonie Van Leeuwenhoek. 50: 305-320. doi: https://doi.org/10.1007/BF00394644.

Huang, R., G. Q. Li, J. Zhang, L. Yang, H. J. Che, D. H. Jiang, and H. C. Huang. 2011. Control of Postharvest Botrytis Fruit Rot of Strawberry by Volatile Organic Compounds of Candida intermedia. Phytopathology 101: 859-869. doi: https://doi. org/10.1094/PHYTO-09-10-0255.

InfoStat 2008. InfoStat, versión 2008. Manual del Usuario. Grupo InfoStat, FCA, Universidad Nacional de Córdoba. Editorial Brujas. Argentina.

ISTA (International Seed Testing Association). 2017. International rules for seed testing. Ed. ISTA. Suiza.

Koopman, W. J., E. Guetta, C. C. van de Wiel, B. Vosman, and R. G. van den Berg. 1998. Phylogenetic relationships among Lactuca (Asteraceae) species and related genera based on ITS-1 DNA sequences. Am. J. Bot. 85: 1517-1530.

Kremer, R. J., A. J. Caesar, and T. Souissi. 2006. Soilborne microorganisms of Euphorbia are potential biological control agents of the invasive weed leafy spurge. Appl. Soil Ecol. 32: 27-37. doi: https://doi.org/10.1016/j.apsoil.2004.12.009.

Liu, Y. Y., H. W. Chen, and J. Y. Chou. 2016. Variation in Indole3-Acetic Acid Production by Wild Saccharomyces cerevisiae and S. paradoxus Strains from Diverse Ecological Sources and Its Effect on Growth. PLOS ONE. doi: https://doi. org/10.1371/journal.pone.0160524.

Marcos-Filho, J. 2015. Seed vigor testing: An overview of the past, present and future perspective. Sci. Agric. 72: 363-374. doi: https://doi.org/10.1590/0103-9016-2015-0007.

Matilla, A. J. 2008. Desarrollo y germinación de las semillas. pp. 537-558. In: J. Azcón-Bieto y M. Talón M. (eds.). Fundamentos de fisiología vegetal. Publicacions i Edicions de la Universitat de Barcelona. España. ISBN: 978-84-481-9293-8

Mou, B. 2008. Lettuce. pp. 75-116. In: J. Prohens and F. Nuez (eds.). Vegetables I, Asteraceae, Brassicaceae, Chenopodicaceae, and Cucurbitaceae. Handbook of plant breeding. Springer. New York, NY, USA. Softcover ISBN: 978-1-4419-2474-2.

Nally, M. C., V. M. Pesce, Y. P. Maturano, C. J. Muñoz, M. Combina, M. E. Toro, L. I. Castellanos de Figueroa, and F. Vazquez. 2012. Biocontrol of Botrytis cinerea in table grapes by non-pathogenic indigenous Saccharomyces cerevisiae yeast isolated from viticultural enviroments in Argentina. Postharvest Biol. Technol. 64: 40-48. doi: https://doi. org/10.1016/j.postharvbio.2011.09.009.
Nally, M. C., M. Lencinas, V. M. Pesce, B. Flores, P. Pedrozo, M. E. Toro, and F. Vazquez. 2018. Possible antifungal action mechanisms of viticulture yeasts against Botrytis cinerea isolated from lettuce. 34 Simposio International Specialized Symposium of Yeast. Bariloche, Argentina.

Nicot, P. C. 2011. Classical and augmentative biological control against diseases and pests: Critical status analysis and review of factors influencing their success. IOBC/WPRS. Avignon, France. ISBN: 978-92-9067-243-2.

Noel, T. C., C. Sheng, C. K. Yost, R. P. Pharis, and M. F. Hynes. 1996. Rhizobium leguminosarum as a plant growth promoting rhizobacterium: direct growth promotion of Canola and Lettuce. Can. J. Microbiol. 42: 279-283. doi: https://doi. org/10.1139/m96-040.

Rabosto, X., M. Carrau, A. Paz, E. Boido, E. Dellacassa, and F. M. Carrau. 2006. Grapes and vineyard soils as sources of microorganisms for biological control of Botrytis cinerea. Am. J. Enol. Vitic. 57: 332-338.

Raid, R. N. 2004. Lettuce diseases and their management. Dis. Fruits Veg. 2: 121-147. doi: https://doi.org/10.1007/1-40202607-2_5.

Rao, R. P., A. Hunter, O. Kashpur, and J. Normanly. 2010. Aberrant synthesis of indole-3-acetic acid in Saccharomyces cerevisiae triggers morphogenic transition, a virulence trait of pathogenic fungi. Genetics 185: 211-220. doi: https://doi. org/10.1534/genetics.109.112854.

Reyes, I., L. Álvarez, H. El-Ayoubi y A. Valery. 2008. Selección y evaluación de rizobacterias promotoras del crecimiento en pimentón y maíz. Bioagro 20: 37-48.

Sobrero, M. C. y A. Ronco. 2004. Ensayo de toxicidad aguda con semillas de lechuga (Lactuca sativa L.). pp. 71-79. In: G. Castillo Morales (ed.). Ensayos toxicológicos y métodos de evaluación de calidad de aguas. Estandarización, intercalibración, resultados y aplicaciones. IDRC, IMTA. Ottawa, Canadá. ISBN: 968-5536-33-3.

Sowley, E. N. K., F. M. Dewey, and M. W. Shaw. 2009. Persistent, symptomless, systemic, and seed-borne infection of lettuce by Botrytis cinerea. Eur. J. Plant Pathol. 126: 61-71. doi: https://doi.org/10.1007/s10658-009-9524-1.

Suliasih, A. and S. Widawati. 2017. Effect of plant growth promoting rhizobacteria and molasses on seed germination and seedling growth of Sorghum bicolor L. Moench. The $1^{\text {st }}$ Satreps Conference, Bogor Nov 14 ${ }^{\text {th }}, 2016$. The project for producing biomass energy and material through revegetation of Alang-alang (Imperata cylindrica) fields. pp. 94-99. Bogor, Indonesia.

Sylla, J., B. W. Alsanius, E. Krüger, and W. Wohanka. 2015. Control of Botrytis cinerea in strawberries by biological control agents applied as single or combined treatments. Eur. J. Plant Pathol. 143: 461-471. doi: https://doi.org/10.1007/ s10658-015-0698-4.

Szczesny, A. F., E. G. Adlercreutz, R. D. Huarte, A. López Camelo, E. Manzo y L. E. Viglianchino. 2014. Producción hortícola bajo cubierta. Instituto Nacional de Tecnología Agropecuaria (INTA). Ciudad Autónoma de Buenos Aires, Argentina. ISBN: 978-987-521-458-3.

Taiz, L. and E. Zeiger. 2006. Plant physiology. Sinauer Associates Inc. Sunderland, MA, USA. ISBN 13: 9780878938568. 
Tawfiq, A. A., M. R. Al-Shaheen, and M. H. I. Al-ani. 2018. Gibberellic acid (GA 3) productions from regular dry bakery yeast (Saccharomyces cerevisiae). J. Adv. Chem. Eng. 3: 24-26.

Williamson, B., B. Tudzynski, P. Tudzynski, and J. A. L. Van Kan. 2007. Botrytis cinerea: The cause of grey mould disease. Mol. Plant Pathol. 8: 561-580. doi: https://doi.org/10.1111/j.13643703.2007.00417.x.
Yahaya, S. M., L. D. Fagwalawa, and M. Lawan. 2015. Influence of airborne and seed inoculum in the initiation of leaf, stem, and root infection by systemic Botrytis cinerea in lettuce (Lactuca sativa). J. Plant Pathol. Microbiol. 6: 1-5. doi: https:// doi.org/10.4172/2157-7471.1000323. 